\title{
Nivelando Conhecimentos Matemáticos: uma ação de Equidade Educacional desenvolvida na Escola Gustavo Barroso em Jaguaribe-Ceará
}

\author{
Cleomar Maciel de Araújo Vieira \\ Manoela de Sousa Dias
}

Ana Samara França Miranda

\section{Resumo}

O presente relato tem por finalidade apresentar as atividades de uma ação educacional desenvolvida pelos professores de matemática da Escola de Ensino Médio Gustavo Barroso, situada no município de Jaguaribe, no Ceará. A ação intitulada por "Nivelando Conhecimentos Matemáticos" surgiu a partir da inquietação dos professores de matemática da instituição que diante dos constantes índices de reprovação na disciplina e do desempenho crítico ou muito crítico em avaliações externas como o SPAECE, decidiram modificar suas estratégias de ensino. Baseando-se em uma avaliação diagnóstica elaborada e aplicada pelos professores, os alunos da terceira série do ensino médio foram divididos, de acordo com seu nível de aprendizagem, em três grupos (critico, intermediário e adequado), os quais ficaram sob a responsabilidade de um professor de matemática que passou a ministrar suas aulas em conformidade com o estágio em que cada aluno se encontrava. As atividades desenvolvidas a partir de então se fundamentavam no princípio de equidade, pois não adiantava mais ensinar da mesma forma para alunos com perfis de aprendizagem bastante diferenciados. $\mathrm{O}$ objetivo da prática aqui exposta era justamente ensinar matemática para os alunos do ensino médio adotando a noção de equidade educacional, proposta por alguns autores como Saviani (1998) e Silva (2016). Os resultados da ação evidenciam um considerável crescimento na aprovação interna da disciplina de matemática, bem como, um expressivo aumento na proficiência do SPAECE no ano de 2018 e maior interesse por parte dos alunos em outras avaliações como o ENEM e OBMEP.

Palavras-chave: Equidade educacional. Ensino. Aprendizagem Matemática. 


\title{
Leveling Mathematical Knowledge: an Educational Equity action developed at the Gustavo Barroso School in Jaguaribe- Ceará
}

\author{
Cleomar Maciel de Araújo Vieira \\ Manoela de Sousa Dias \\ Ana Samara França Miranda
}

\begin{abstract}
This report has as its activities an educational action developed by the mathematics teachers at the Gustavo Barroso High School, located in the municipality of Jaguaribe, Ceará. The action entitled "Leveling Mathematical Knowledge" arose from the concern of the institution's mathematics teachers that occurs due to the constant failure in the discipline and the critical or very critical performance in external assessments such as SPAECE, decided to modify their teaching strategies. Based on a diagnostic assessment developed and applied by teachers, students in the third grade of high school were divided, according to their level of learning, into three groups (critical, intermediate and appropriate), who were notified under the responsibility of a mathematics teacher who started to teach his classes in compliance with the internship in which each student was. The activities developed since then were based on the principle of equity, since it was no use using the same way for students with very different learning profiles. The purpose of the practice exposed here was precisely to use mathematics for high school students adopting a notion of educational equity, proposed by some authors such as Saviani (1998) and Silva (2016). The results of the action show an increase in the internal approval of the discipline of mathematics, as well as a significant increase in the proficiency of SPAECE in the year 2018 and greater interest on the part of students in other assessments such as ENEM and OBMEP.
\end{abstract}

Keywords: Educational equity. Teaching. Mathematical Learning. 


\section{Introdução}

Um dos grandes obstáculos para que a Escola de Ensino Médio Gustavo Barroso, localizada no distrito de Nova Floresta, município de Jaguaribe, no interior do estado do Ceará obtivesse bons resultados, sejam eles internos ou externos, sempre foi a disciplina de matemática. Ao longo dos últimos anos, este foi o componente curricular em que mais alunos ficaram para recuperação, progressão parcial ou reprovação. Essa era uma realidade que, apesar das inúmeras tentativas, tendia a se manter, carecendo um olhar sempre mais atento da escola, sobretudo em termos de equidade, uma vez que a instituição não estava conseguindo lidar com as discrepâncias relativas a conhecimento apresentadas pelos seus diversos alunos.

Pelo fato de ser a única escola de Ensino Médio da localidade, em uma mesma turma, muitas vezes, existia uma diversidade de alunos - alunos de zona urbana, rural, oriundos da Educação de Jovens e Adultos, ensino noturno, ensino regular - e, com isso, uma grande quantidade de aprendizagens diferenciadas, o que exigia do professor um ensino também diferenciado, algo que não estava acontecendo, dado o elevado número de conteúdos a serem ministrados, as peculiaridades das turmas e a presença de um único professor em sala, o qual tentava balancear o nível de abordagem do conteúdo para tentar atender, ao mesmo tempo, os alunos considerados bons, assim como, aqueles que possuíam muitas dificuldades e que, de certa forma, não conseguiam acompanhar os temas trabalhados pelo professor.

Nesse sentido, uma mudança de atitude frente a esta problemática e a implementação de uma prática que modificasse os resultados da disciplina de Matemática eram urgentes e foi justamente esse desejo o que motivou os professores de matemática da instituição para o desenvolvimento da ação "Nivelando Conhecimentos Matemáticos" no ano de 2018, com três turmas de $3^{\circ}$ ano e que aqui será exposta.

\section{O contexto}

Conforme citado anteriormente, a Escola Gustavo Barroso vinha enfrentando nos últimos anos uma elevação considerável no número de alunos em recuperação na disciplina de matemática, a partir de sua avaliação interna, como pode ser observado no gráfico o1. No mesmo gráfico, também é possível identificar que de 2014 a 2017 houve um considerável aumento de alunos entre os que não conseguiram atingir a pontuação mínima necessária para ser considerado aprovado na disciplina. Vale salientar que a unidade de ensino utiliza diversas estratégias de avaliação, dentre elas as atividades individuais, em grupo, seminários, aulas de campo e a tradicional avaliação escrita. A cada bimestre, o professor aplica uma prova escrita e mais outra atividade das citadas acima e a partir disso, tem-se a nota do aluno. Para ser considerado aprovado, o aluno precisa ter um desempenho de, no mínimo, 60\% na somatória das notas de todas as atividades realizadas.

ISSN 2526-2882 
Gráfico 01 - Levantamento longitudinal da recuperação em matemática na EEM Gustavo Barroso

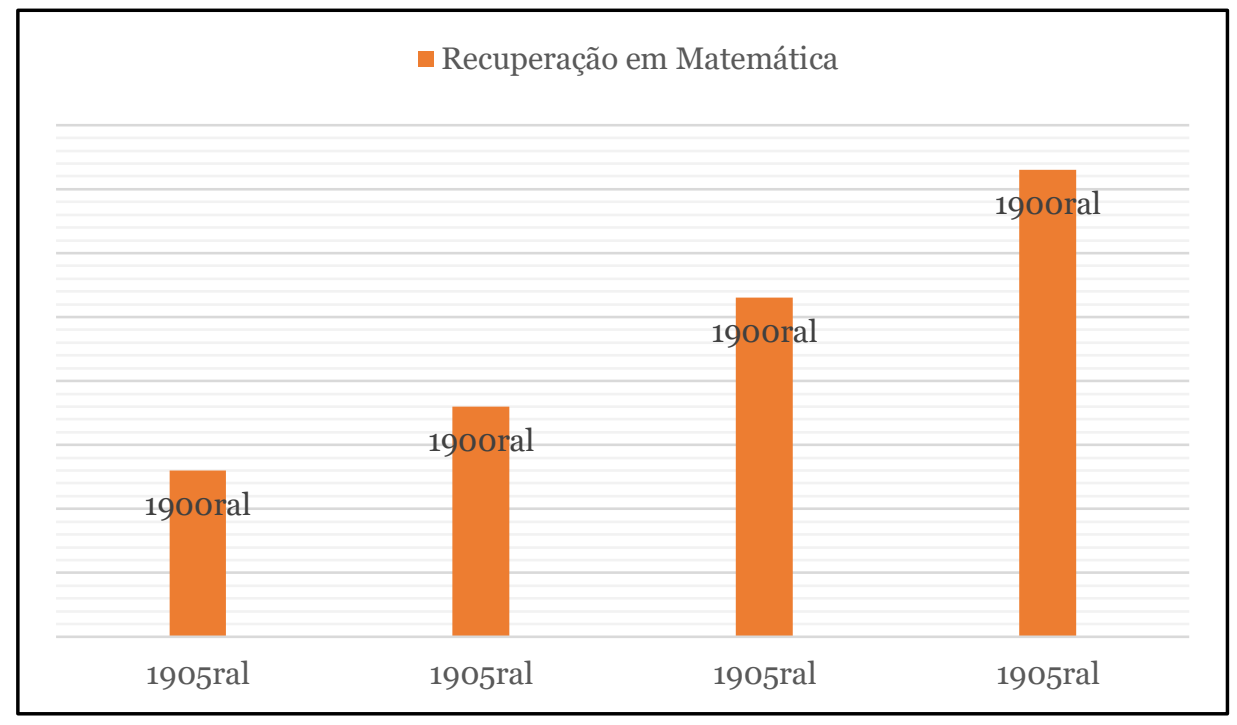

Fonte: Elaboração própria com base em dados da secretaria escolar

No ano de 2018, dados retirados do Sistema Integrado de Gestão Escolar (SIGE Escola) ${ }^{1}$ no primeiro bimestre apontavam para uma continuidade dessa situação, uma vez que em todas as 10 turmas da instituição de ensino, a disciplina apresentou-se novamente como crítica. Em relação às avaliações externas, os resultados do Sistema Permanente de Avaliação da Educação Básica do Ceará (SPAECE), avaliação em larga escala promovida anualmente pela Secretaria de Educação do Estado do Ceará (SEDUC), revelavam uma flutuação no desempenho dos alunos da terceira série do ensino médio, sendo maior o histórico de quedas do que o de crescimento.

De acordo como o gráfico 02, de 2012 para 2013, aconteceu uma queda relevante de 2,4 pontos no desempenho dos alunos da terceira série da instituição. Em 2014, a escola conseguiu recuperar o que havia perdido, já que obteve um aumento de 3,6 pontos em se comparando com o ano passado. Em 2016 ocorreu novamente uma ligeira queda de o,8 pontos, que se acentuou ainda mais em 2017, caindo 3,6 pontos, um dos piores resultados da escola na série história do SPAECE, que iniciou sua avaliação de forma censitária no ano de 2012.

${ }^{1}$ O Sistem Integrado de Gestão (SIGE Escola) é um sistema informatizado que contém todos os dados dos alunos da rede estuadual do Ceará. Os dados vão desde a documentação do aluno ao seu desempenho acadêmico e de frequência e está interligado com outros sistemas da rede, os quais fornecem informações importantes do aluno para a gestão escolar, professores e para a própria Secretaria da Educação, desenvolvimento de suas políticas públicas educacionais a nível estadual. 


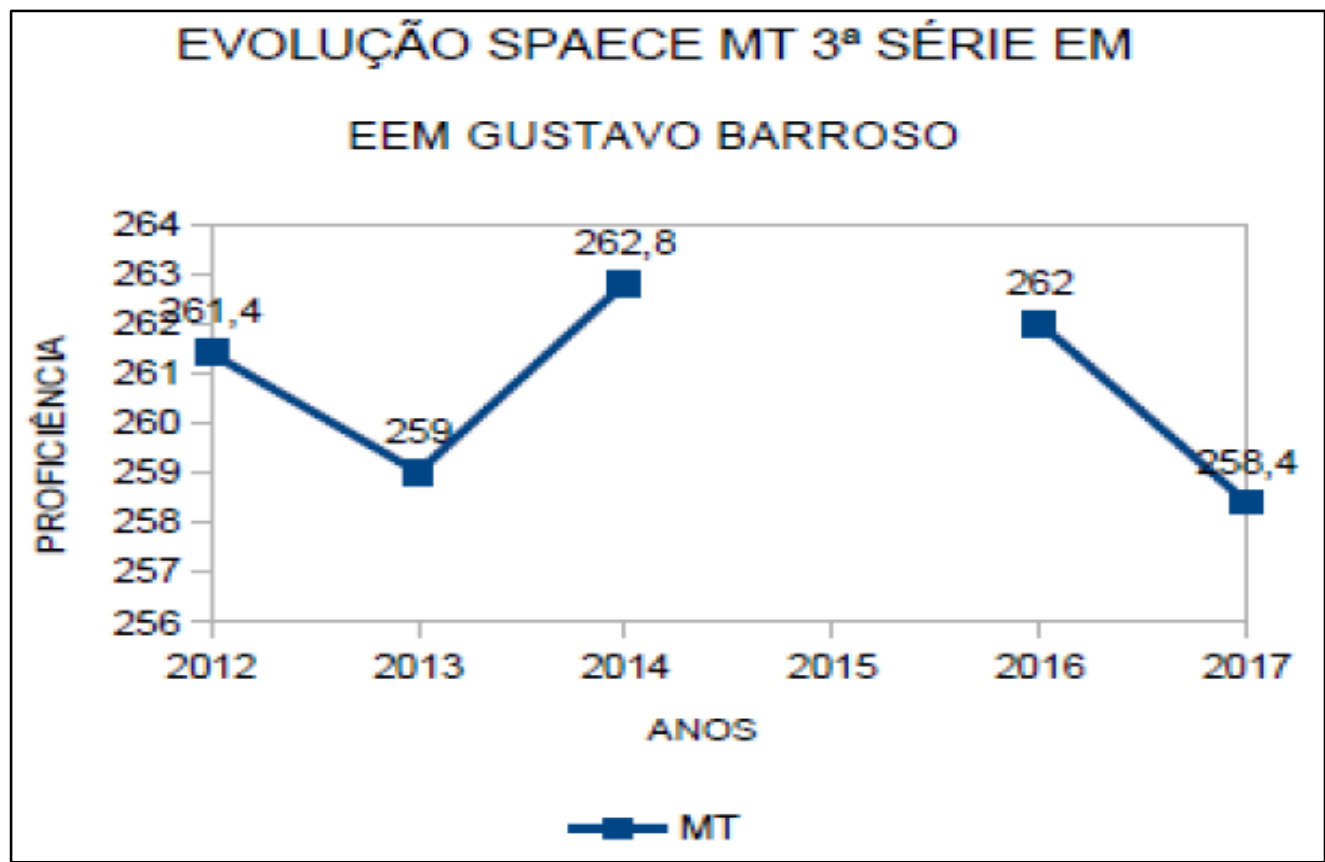

Fonte: CAED/UFJF

Esse constante decréscimento no resultado escolar e o desempenho obtido em 2017 no SPAECE, pode ser apontado como uma das causas para a escola não ter atingido sua meta de 3,88 no Índice de Desenvolvimento do Ensino Médio (IDE-Médio), indicador estadual que usa a mesma base de cálculo do Índice de Desenvolvimento da Educação Básica (Ideb). O resultado alcançado foi de apenas 3,76.

Quando questionados sobre essa situação, os professores de matemática da escola alegavam que a falta de "base" dos alunos em relação a conteúdos essenciais do ensino fundamental é um fator que tem dificultado bastante o seu trabalho, uma vez que, muitas vezes, precisam estar retomando alguns temas que já deveriam ter sido consolidados, para só assim adentrarem na proposta do ensino médio. Isso tem atrasado o cumprimento do plano de curso da disciplina, acarretando, inclusive, na não abordagem de alguns temas, gerando prejuízos para as séries seguintes.

A maioria dos assuntos tratados no ensino médio requerem do aluno o domínio sobre competências e habilidades do nível anterior, ou seja, do ensino fundamental. Sem isso, tornase praticamente impossível qualquer iniciativa da escola, por mais bem-intencionada que seja. "Para mudar, é preciso agir na questão do desnível dos nossos educandos, caso contrário, faremos o mesmo feito no ensino fundamental: empurrando os alunos para a série seguinte

${ }^{2}$ Em 2015 a avaliação do SPAECE foi realizada somente com a turma de $1^{\circ}$ Ano, por isso a ruptura dos dados no gráfico 02. 
sem os domínios necessários para a continuidade nos estudos” (M. R. - professor de Matemática da Escola).

O consenso entre os professores de matemática da escola era que a realidade não poderia continuar a acontecer, pois de acordo com as avaliações tanto internas, quanto externas, a escola não estava conseguindo agregar conhecimentos aos alunos. Outra concordância entre os professores era que não adiantava investir apenas nos "bons" alunos e deixar os demais, que são a maioria, para trás.

Era preciso pensar em um ensino que oferecesse recursos pedagógicos para o aluno em consonância com o seu nível de aprendizagem, partindo da ideia de que para melhorar os indicadores da escola, todos precisavam progredir, mesmo que em ritmos diferenciados, com equidade. Foi aí que nos deparamos com o seguinte problema: como a Escola de Ensino Médio Gustavo Barroso poderia melhorar a aprendizagem de seus alunos e consequentemente seus resultados internos e externos, adotando como parâmetro o princípio da equidade educacional? Partindo da questão exposta, a escola sentiu-se impelida a realizar uma ação que conseguisse minimizar ou extinguir tal conjuntura, passando a enfrentá-la como algo prioritário.

\section{Procedimentos de Planejamento e Execução da Ação}

A prática aqui relatada começou a se desenhar a partir de uma reflexão promovida pela coordenação escolar junto aos professores de matemática ante os resultados não tão satisfatórios da disciplina no primeiro período de 2018 e o histórico de baixo desempenho dos alunos nas avaliações em anos anteriores. Nesse encontro, alguns pontos foram levantados, dentre eles a metodologia de ensino adotada pelos professores. O coordenador escolar observou que a escola não conseguiria obter êxito no seu processo de ensino e aprendizagem até que modificasse consideravelmente a forma de se abordar os assuntos lecionados. Não adiantaria trabalhar da mesma forma para todos os alunos, pois cada um tinha dificuldades individualizadas, algo que o ensino tradicional não estava conseguindo suprir. Portanto, a primeira coisa a ser feita seria perceber os diversos níveis de aprendizagem em que cada aluno se encontrava para só então, desenvolver um itinerário formativo.

A atividade inicial foi a elaboração e aplicação, pelos próprios professores, de uma avaliação diagnóstica contemplando alguns dos descritores de matemática do SPAECE da terceira série. A escolha dessa série se deu pelo fato de, no ano de 2017, os alunos do então segundo ano terem sido os mais críticos de toda a escola na disciplina de matemática. Além disso, a última série da educação básica é o foco das principais avaliações de larga escala, tais com SPAECE e SAEB, o que requer maior atenção por parte da gestão escolar e dos professores.

A avaliação diagnóstica tinha por objetivo identificar os níveis de proficiência de cada aluno, para que, partindo do princípio da equidade, algumas atitudes fossem tomadas. Saviani 
(1998) compreende a equidade como um equilíbrio entre o mérito e a recompensa e, dessa forma, questiona a substituição do conceito de igualdade pelo de equidade na formulação de políticas educacionais.

Em se tratando de matemática Silva (2016, p. 407) coloca que:

A questão da equidade vem sendo debatida na educação matemática há vários anos, permeando diversos aspectos, como busca por oportunidades de acesso e engajamento para todos os estudantes independentemente de suas características individuais, sociais e econômicas, foco nas lacunas de desempenho entre grupos de estudantes, críticas e reformulações do currículo da matemática escolar e também sobre novas perspectivas de ensino que abordam situações de injustiça e inequidades na sociedade.

A equidade é, portanto, uma maneira de superar as desigualdades presentes nos sistemas de ensino e que ao que tudo indica ainda não estão com os dias contados. Refletir sobre estes aspectos parece ser um bom começo e foi isso que fizemos enquanto instituição de ensino.

Com base nestes ideais e nos resultados do diagnóstico, os alunos do terceiro ano foram divididos em três grupos, conforme suas necessidades cognitivas. Os grupos foram os seguintes: grupo crítico - 25\% a 30\% de acertos no diagnóstico; intermediário - de 31 a 60\% de acertos; e, adequado - acima de 60\% de acertos na avaliação. Os itens do teste eram similares aos do SPAECE e tinham nível de dificuldade variando entre fácil e médio. Os grupos crítico, intermediário e adequado ficaram, em média, com 50\%, 35\% e 15\% dos alunos matriculados no terceiro ano, respectivamente.

Cada agrupamento de alunos ficou sob a responsabilidade de um dos três professores de matemática da escola, o qual preparava suas aulas tendo em vista o estágio em que cada aluno se encontrava. O professor que ficou responsável pelo nível crítico, por exemplo, planejava e ministrava suas aulas tendo em vista esse grupo de alunos, o que facilitava a compreensão, uma vez que eles possuíam competências e habilidades semelhantes. Algo idêntico acontecia com os padrões intermediário e adequado. Um aspecto que também favoreceu essa ação foi o fato de os professores além de terem os alunos em ritmos de aprendizagem similares, tinham o número de alunos menor do que o percebido na turma convencional, já que as turmas eram divididas. Em 2018 a instituição de ensino possuía três turmas de terceiro ano e as atividades foram desenvolvidas separadamente em cada uma. As aulas aconteciam uma vez por semana e os professores, em conjunto, entravam em sala e realizavam suas aulas.

A intenção era que houvesse uma progressiva migração, ao longo do ano, dos alunos do grupo com maiores dificuldades, ou dos intermediários, para o adequado, até que toda a classe ou a maioria dela estivesse nesse nível, tendo como prazo o final do ano letivo de 2018. 
Para isso, os professores de cada equipe aplicavam testes mensalmente para identificar se os alunos estavam aptos a mudar de um estágio para o outro.

Os professores foram os grandes entusiastas desta ação. A disponibilidade em favorecer a aprendizagem de seus alunos, como forma de melhorar o resultado da escola, foi o ponto de partida e o que mais os motivou no desenvolvimento das aulas com foco no avanço de todos e não apenas de uma minoria dos alunos. As aulas contavam com materiais lúdicos e atividades pedagógicas diferenciadas, principalmente para os que possuíam maiores necessidades, isso exigiu um planejamento mais específico, mas foi recompensado, como poderá ser visto a seguir.

\section{As mudanças (Impactos da Ação)}

Para efeitos de comparação de resultados internos, a escola adotou o quantitativo de alunos da terceira série que estava abaixo da média no primeiro bimestre como parâmetro, quando a ação ainda não estava em execução. No ciclo em questão, ficaram 27 alunos em recuperação, o que corresponde a 35,52\% da matrícula na referida série.

No segundo, terceiro e quarto bimestres, quando a prática já estava em andamento, o número de alunos com nota inferior à média manteve-se sempre abaixo do resultado percebido no período de referência. Ademais, a fração dos alunos de recuperação em 2018, na terceira série, caiu significativamente em relação a 2017, neste ano, 20 alunos da série supracitada ficaram em recuperação. Já em 2018, esse resultado foi reduzido em 50\%, passando a ser apenas 10 alunos em um universo de 73, o que equivale a 13, 69\% do alunado da série estudada.

Em relação ao SPAECE, os resultados são ainda mais animadores. Como verificado no gráfico 03, de 2016 a 2017, houve uma queda de 3,6 pontos, quando a instituição ainda não desenvolvia a ação. A partir do ano de 2018, quando os alunos passaram a receber as aulas de acordo com seu ritmo de aprendizagem, os resultados melhoraram expressivamente. De 2017 a 2018, a terceira série cresceu 28,1 pontos, algo que nunca aconteceu em toda a história da instituição, o maior crescimento da regional em que a escola está inserida e um dos maiores crescimentos entre as escolas de ensino médio do estado do Ceará. Outro fator que também merece destaque é o envolvimento e comprometimento dos alunos não só com o SPAECE, mas também com outras avaliações externas, tal como ENEM e OBMEP. 


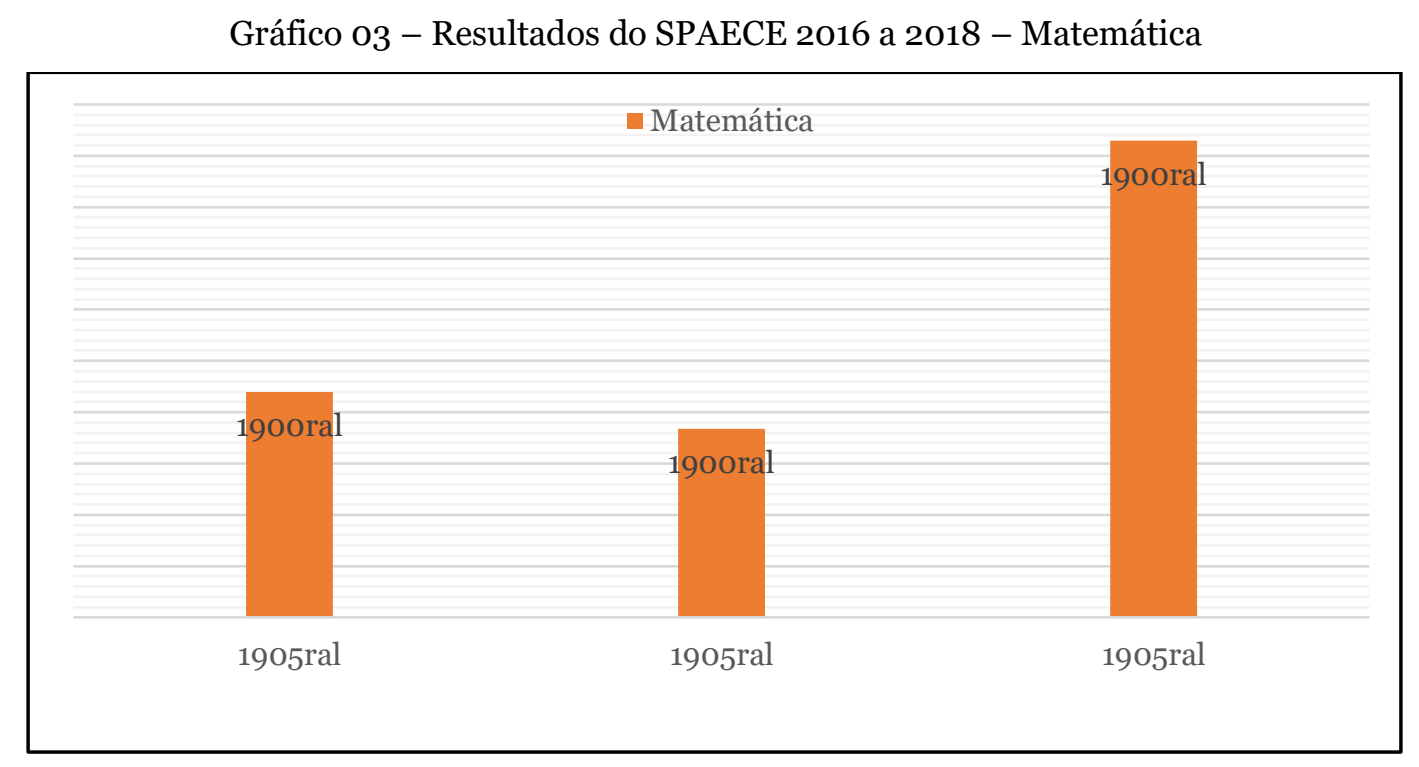

Fonte: Elaboração própria com base em dados do CAED/UFJF

\section{Reflexões sobre a Ação}

A ação desenvolvida pelos professores mostrou que o ensino da matemática precisa começar a considerar o nível de cognição de cada aluno e a partir disso, pensar em metodologias e práticas que possibilitem o progresso de todos. Imaginar que um aluno com dificuldades relacionadas às quatro operações pode acompanhar, por exemplo, equações do segundo grau com a mesma facilidade que um aluno que possui todos os domínios aritméticos é utópico e um erro no qual algumas escolas ainda persistem em cometer, gerando exclusão e segregação dos alunos, sobretudo em um cenário que a cada dia requer mais conhecimento matemático por parte do aluno egresso do ensino médio.

De acordo com Silva (2016, p.402) "por questões fortemente relacionadas à raça, gênero, classe, etnia, religião, idioma e classes sociais, uma variedade de grupos tem sido excluída dos contextos sociais nos quais há a predominância da matemática”.

Ao entendermos que o caminho da escola se dá em sentido contrário ao da exclusão, passamos a trabalhar na perspectiva de fazer com que todos os alunos conseguissem avançar, com o intuito de tentarmos corrigir as desigualdades de aprendizagem às quais esses jovens foram submetidos ao longo de sua vida escolar. Mais uma justificativa para escolhermos a terceira série do ensino médio, uma vez que essa poderia ser a nossa última chance de oferecermos a alguns dos adolescentes, prestes a concluir a educação básica, um momento significativo com a ciência dos números, algo que provavelmente no decorrer de toda sua história acadêmica não tenha acontecido ou tenha sido dado com algumas restrições.

Nesse sentido, alguns pesquisadores como a americana Jo Boaler, da Universidade de Stanford (EUA), em seu livro "Mentalidades Matemáticas: estimulando o potencial dos estudantes por meio da matemática criativa, das mensagens inspiradoras e do ensino 
inovador" levanta a discussão de que todos estão aptos a aprender matemática, independentemente da classe social, idade, gênero ou etnia. A pesquisadora desfaz a crença de que a disciplina é apenas para um conjunto de privilegiados ou "superdotados" e reforça a ideia de que a matemática escolar deve estar voltada para todos, inclusive em níveis mais elevados.

Com todas essas motivações, o trabalho foi iniciado. As dificuldades foram surgindo durante o percurso e precisaram ser corrigidas. O maior desafio foi agregar três professores em uma única turma para trabalhar com alunos em padrões de aprendizagens distintos. Conseguimos superar esse obstáculo com a ajuda da gestão escolar que criou horários compatíveis para que os professores estivessem disponíveis para a ministração das aulas nas três turmas. Além disso, o planejamento teve que ser modificado em razão da peculiaridade de se ensinar de acordo com a proficiência do aluno. Isso exigiu mais dedicação por parte de cada professor, bem como a adoção de diversos recursos pedagógicos a fim de facilitarem a compreensão dos assuntos abordados e a elaboração de instrumentais avaliativos que permitissem identificar os avanços e as mudanças de um estágio para outro.

Os alunos também estranharam a metodologia, mas conseguiram se adaptar rapidamente, pois à medida que conseguiam entender o que o professor estava explicando, entenderam também a iniciativa da escola em fazer os agrupamentos. O mesmo aconteceu com os pais dos alunos. Todo e qualquer embaraço era superado quando imaginávamos que esta poderia ser uma das nossas últimas ações com vistas na evolução da aprendizagem dos alunos, já que tantas outras haviam sido executadas, porém sem o devido êxito. Na verdade, sentíamos que, em essência, as atividades realizadas eram muito valorosas e imbuídas de um sentido de inclusão. Por esse motivo, além dos outros já retratados, aplicamos o piloto da ação com os alunos da terceira série do ensino médio.

Convém ressaltar que os alunos foram divididos por nível de proficiência em três das quatro aulas de matemática que ocorriam ao longo da semana. Na quarta aula semanal os alunos realizavam tarefas compatíveis a todos os níveis e também faziam as avaliações para mudança de um grupo para outro. É importante destacar que em nenhum momento houve qualquer constrangimento por parte dos alunos em relação ao nível em que cada um se encontrava, principalmente os do padrão crítico. Na realidade, essa divisão por padrões estava muito clara apenas para os professores e gestores escolares. Para os alunos, a separação das equipes estava acontecendo para facilitar o ensino de matemática em virtude dos baixos indicadores da escola em avaliações internas e externas.

Tanto por parte dos professores quanto dos alunos havia a consciência de que os resultados da instituição não poderiam mais permanecer da forma como vinham se desenhando e essa inquietação proporcionou a guinada nos indicadores internos e externos da unidade de ensino, inclusive o IDE-Médio. Esse crescimento foi bem mais evidente na terceira série, onde a ação foi desenvolvida. 
Diante do êxito da ação, a escola a estendeu, no ano de 2019, para todas as turmas do ensino médio, uma vez que os resultados percebidos no terceiro ano de 2018 apontaram para melhorias significativas nos indicadores escolares.

Em 2019, pelos dados preliminares do SPAECE³, a escola conseguiu crescer em torno de oito pontos, aproximando-se do nível de proficiência intermediário na avaliação estadual de larga escala ${ }^{4}$. Cabe salientar que no começo da ação, no ano 2018, tomando como referência os dados do SPAECE de 2017, conforme pode ser visto no gráfico 03, a instituição encontravase com 258,4 pontos, ou seja, praticamente no incio da escala crítica.

No ano de 2019, com a continuadade da ação não só na terceira série, como também em outras turmas, a pontuação alcançada no SPAECE foi de 295,3. Verificando-se, portanto, um crescimento de quase 37 pontos em apenas dois anos de execução da ação de nivelamento matemático que ora fazemos a exposição, mais um fator que comprova a sua necessidade não somente na terceira série, mas em todas as turmas do ensino médio.

\section{Referências}

BOALER, J. Mentalidades Matemáticas: estimulando o potencial dos estudantes por meio da matemática criativa, das mensagens inspiradoras e do ensino inovador. São Paulo: Penso, 2018.

BOLETIM SPAECE 2012, 2013, 2014, 2016, 2017 e 2018 [da] Secretaria da Educação do Estado do Ceará. $\quad$ Fortaleza, 2019. Disponível em: $<$ http://resultados.caedufjf.net/resultados/publicacao/ publico/escola.jsf $>$. Acesso em: 28 jan. 2018.

SAVIANI, D. ¿Equidad o igualdad en educación? Revista Argentina de Educación, Buenos Aires, v. 16, n. 69, 1998, p. 27-31. Disponível em:< http://132.248.192.201/seccion/bd_iresie/iresie_busqueda.php?indice=autor\&bus queda=SAVIANI,\%2oDERMEVAL\&par=\&a_inicial=\&a_final=\&sesion=\&formato=l argo >. Acesso em: 31 jan. 2019.

SILVA, G. H. G. Equidade e educação matemática. Educação Matemática Pesquisa, São Paulo, v.18, n.1, 2016, p. 397-420. Disponível em: <https://revistas.pucsp.br/index.php/emp/article/view /21081>. Acesso em: 28 jan. 2019 .

3 Os resultados finais do SPAECE 2019 ainda na foram divulgados em virtude pandemia da COVID-19, porém cada escola e a própria rede de ensino já dispõem de resultados preliminares.

4 A escala da SPAECE é divida em quatro níveis de proficiência (muito crítco, crítico, intermeidário e adequado), com intervalos de 50 pontos entre cada padrão de desempenho. A saber: muito crítico, até 250 pontos; crítico de 250 a 300 pontos; intermediário, de 300 a 350 pontos; e, adequadado, acima de 350 pontos. 


\section{Biografia Resumida}

Cleomar Maciel de Araújo Vieira: Licenciado em Matemática pelo IFCE; Especialista em Matemática e Física pela FJN; Mestre em Gestão e Avaliação da Educação Pública pela UFJF; Professor de Matemática na Escola Gustavo Barroso.

Lattes: http://lattes.cnpq.br/2026214262237056

Contato: cleomarprof@gmail.com

Manoela de Sousa Dias: Licenciada em Matemática pelo IFCE;

Professora de Matemática na Escola Gustavo Barroso.

Lattes: http://lattes.cnpq.br/6812592141573646

Contato:manoeladesousadias@gmail.com

Ana Samara França Miranda: Licenciada em Biologia pelo IFCE; Especialista em Química e Biologia pelo UNIVASF; Professora de Matemática na Escola Gustavo Barroso.

Link do lattes: http://lattes.cnpq.br/6289265367458612

Contato: samara.ifbio@gmail.com 